UDC 621.039.54; 621.039.6

\title{
FUSION NEUTRON SOURCE AS AN EFFECTIVE PRODUCER OF NON-TRADITIONAL NUCLEAR FUEL
}

\author{
G.G. Kulikov, A.N. Shmelev, A.E. Kruglikov, V.A. Apse, E.G. Kulikov
}

\author{
National Research Nuclear University MEPhI, Moscow, Russia
}

The paper aims at studying peculiarities in isotope composition of thorium blanket under irradiation by fusion neutron source (FNS) in hybrid thermonuclear reactor (HTR). High-energy (14 MeV) component of neutron spectrum in thorium HTR blanket can produce nontraditional fissile mixture including not only ${ }^{233} \mathrm{U}$, but also ${ }^{231} \mathrm{~Pa},{ }^{232} \mathrm{U}$ and ${ }^{234} \mathrm{U}$. The extraction of such non-traditional fuel from a spent Th-blanket and its utilization in traditional nuclear power reactors could increase fuel burnup and contribute to nuclear weapon nonproliferation. The results of a comprehensive investigation of the above positive effects, which included high-precision neutronics analyses of a HTR's Th blanket, are presented. The chosen model of HTR allowed the formation of high-energy neutron spectrum in Th-blanket with significant fraction of $14-\mathrm{MeV}$ neutrons; it appeared that threshold $(n, 2 n)$ - and $(n, 3 n)$-reactions are able to produce significant amounts of non-traditional target isotopes ${ }^{231} \mathrm{~Pa}$ and ${ }^{232} \mathrm{U}$; it was shown that accumulation of non-traditional target isotopes weakened substantially in depth of Th-blanket. It is therefore reasonable to look for optimal thickness of Th-blanket and optimal inventory of natural thorium.

Key words: hybrid thermonuclear reactor, fusion neutron source, thorium blanket, ${ }^{231} \mathrm{~Pa},{ }^{232} \mathrm{U}$, computer code SERPENT-2.

DOI: $10.21517 / 0202-3822-2021-44-2-124-132$

\section{ТЕРМОЯДЕРНЫЙ НЕЙТРОННЫЙ ИСТОЧНИК - ЭФФЕКТИВНЫЙ НАРАБОТЧИК НЕТРАДИЦИОННОГО ЯДЕРНОГО ТОПЛИВА}

\author{
Г.Г. Куликов, А.Н. Шмелев, А.Е. Кругликов, В.А. Апсэ, Е.Г. Куликов
}

Национальный исследовательский ядерный университет «МИФИ», Москва, Россия

Анализируются особенности изотопного состава Тh-бланкета при облучении в гибридном термоядерном реакторе (ГТР) на (D-T)-плазме. (D-T)-плазма была выбрана потому, что высокоэнергетическая (14 МэB) составляющая нейтронного спектра в ториевом бланкете ГТР позволяет получать нетрадиционную делящуюся смесь, включающую не только ${ }^{233} \mathrm{U}$, но и изотопы ${ }^{231} \mathrm{~Pa},{ }^{232} \mathrm{U}$ и ${ }^{234} \mathrm{U}$. Такие нетрадиционные топливные композиции могут представлять интерес для проектов АЭС с ядерными реакторами на тепловых нейтронах, поскольку они могут привести к более высокому выгоранию топлива и усилению режима ядерного нераспространения. Исследования этих положительных эффектов потребовали детального нейтронно-физического анализа ториевого бланкета ГТР. В статье представлены результаты, полученные в ходе этих исследований: выбранная модель ГТР позволила сформировать высокоэнергетический нейтронный спектр в Тh-бланкете с значительной долей нейтронов с энергией $14 \mathrm{MэB;} \mathrm{пороговые}(n, 2 n)$ - и $(n, 3 n)$-реакции способны производить значительные количества нетрадиционных изотопов ${ }^{231} \mathrm{~Pa}$ и ${ }^{232} \mathrm{U}$; накопление этих изотопов существенно ослабевает в глубине Тh-бланкета. Поэтому нужно искать оптимальную толщину Th-слоя и оптимальное количество загружаемого в бланкет природного тория.

Ключевые слова: гибридный термоядерный реактор, термоядерный источник нейтронов, ториевый бланкет, ${ }^{231} \mathrm{~Pa},{ }^{232} \mathrm{U}$, компьютерная программа SERPENT-2.

\section{MODEL OF FUSION NEUTRON SOURCE}

High-energy $(14 \mathrm{MeV})$ neutrons present in thorium HTR blanket can produce non-traditional mixes off issionable materials including not only ${ }^{233} \mathrm{U}$, but also ${ }^{231} \mathrm{~Pa},{ }^{232} \mathrm{U}$ and ${ }^{234} \mathrm{U}$. The extraction of those nontraditional fuel sourced from a spent Th-blanket and their subsequent utilization in conventional nuclear

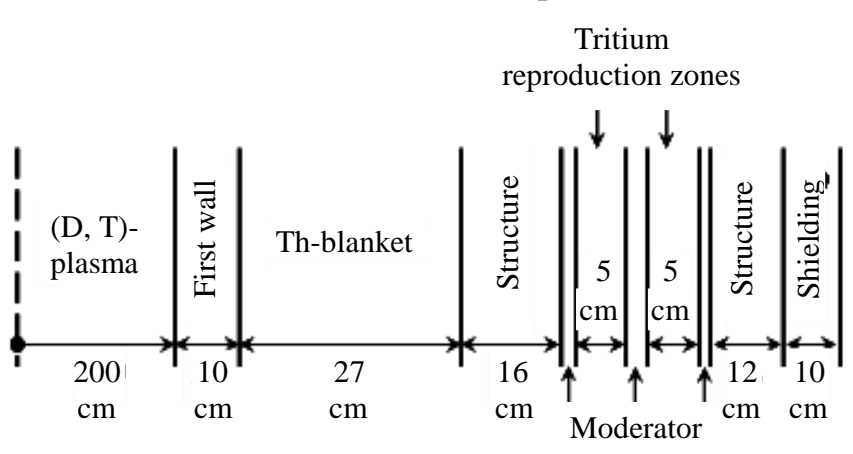

( 2.4 and $1 \mathrm{~cm}$ of $\mathrm{H}_{2} \mathrm{O}$ )

Fig. 1. Basic layout of the HTR model power reactors could increase fuel burn up and enhance nuclear non-proliferation [1-4]. A onedimensional cylindrical HTR model [5] was used in numerical analyses. Radial HTR zones were treated as infinitely long axial layers. An equi component $\mathrm{D}-\mathrm{T}$ plasma $\left(n_{\mathrm{T}}=n_{\mathrm{D}}=5 \cdot 10^{14} \mathrm{ion} / \mathrm{cm}^{3}\right)$ was taken to be the main neutron source. A basic layout of the HTR model is shown in Fig. 1.

The thorium blanket was place dimmediately behind the first wall, to allow high-energy 14-MeV neutrons to irradiate thorium and produce non-traditional 
nuclides via certain threshold reactions. In front of the blanket, fusion neutrons are partially moderated by the first wall. The blanket is separated from the tritium reproduction zones (Li-containing zones) by structural materials. Light-water layers are set in front of, behind and between the tritium reproduction zones to intensify ${ }^{6} \operatorname{Li}(n$, $\alpha)$ T reaction. Neutron senter the tritium reproduction zones after having passed through the tritium blanket and been slowed down. Theses low neutrons do not have the potential to initiate any threshold reaction and can be utilized in the tritium reproduction zones without decreasing the production of non-traditional nuclides.

\section{NEUTRON ANALYSIS OF THORIUM HTR BLANKET}

Time-dependent neutronics analyses of the isotopic content compositions in thorium HTR blanket were carried out using SERPENT-2 Monte Carlo [6-8] with continuous energy dependencies of evaluated nuclear data. The first wall neutron load was taken as $1 \mathrm{MW} / \mathrm{m}^{2}$. This value is generally acceptable from the standpoint of the first wall strength properties.

SERPENT-2code. SERPENT-2 is the multi-purpose computer code based on Monte Carlo methodology. It applies continuous energy dependencies of evaluated micro cross-sections to the solution of three-dimensional transport equations. SERPENT-2 was initially created to solve nuclear reactor physics problems, but now its capabilities extend beyond this. Applications can be divided into the following three categories:

- traditional problems of the nuclear reactor physics: spatial homogenization, determination of reactor criticality, investigations of nuclear fuel cycle, simulation of nuclear research power reactors, validation of deterministic computer codes, etc.;

- multi-physical simulations: neutronics combined with thermal-hydraulic analyses, CFD-code computations, as well as computations that account for variations in fuel properties;

- neutron/photon transport modeling in the estimation of exposure dose — aimed at solving radiation shield problems and conducting nuclear power and medical research.

SERPENT-2 reads continuous energy micro cross-sections from ACE-formatted libraries. The interaction physicsis based on classical kinematics of inter-particle collisions, reaction cross-sections from evaluated nuclear data files (ENDFs) and probability table sampling in the unresolved resonance energy range. ACE-formatted cross-section libraries are based on JEF-2.2, JEFF-3.1, JEFF-3.1.1, ENDF/B-VI.8 and ENDF/B-VII evaluated nuclear data files. Data on radioactive decay and fission yield are taken from standard ENDF-formatted libraries.

Neutron spectrum in Th-blanket. The results of the Th-blanket neutron spectrum calculation are shown in Fig. 2. One can see two peaks, one close to $10 \mathrm{MeV}$, the other close to $0.4 \mathrm{MeV}$. While the former is directly related to fusion neutrons coming from the source, the latter is produced by neutrons that have passed through the first wall, undergone inelastic scattering and lost a significant portion of their initial energy. Neutrons with resonance, epithermal and even thermal energies can be found in deep inner layers of the Th-blanket. The proportion of these slow neutrons is substantially smaller than that of high-energy neutrons. As a result, a sufficiently high-energy neutron spectrum can be formed in the Th-blanket even with a thick $(10 \mathrm{~cm})$ first wall. The proportion of high-energy neutrons increases with decreasing blanket thickness.

Micro cross-sections and reaction rates in Thblanket. This section deals with the basic characteristics that define the Th-blanket performance in terms of producing the important ${ }^{231} \mathrm{~Pa}$ and ${ }^{232} \mathrm{U}$ isotopes. These characteristics are the micro cross-sections of ${ }^{232} \mathrm{Th}$ and neutron flux in different radial zones of Th-blanket at the beginning of irradiation (Fig. 3). Because the ${ }^{232}$ Th burn up will be relatively low when the first wall neutron load sincrease $\left(1 \mathrm{MW} / \mathrm{m}^{2}\right)$ at a certain level of engineering maturity, neutron reactions on ${ }^{232} \mathrm{Th}$ nuclei will define the neutron balance throughout the irradiation cycle.

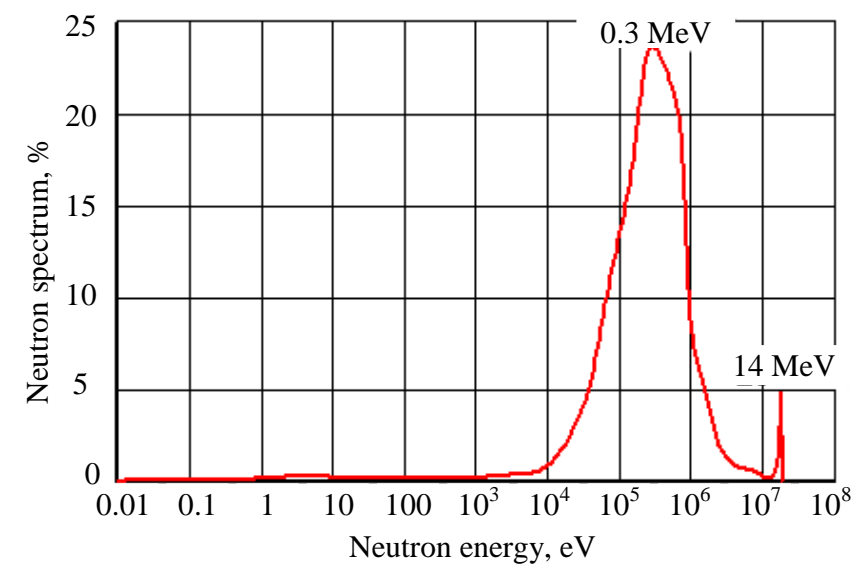

Fig. 2. Th-blanket neutron spectrum 


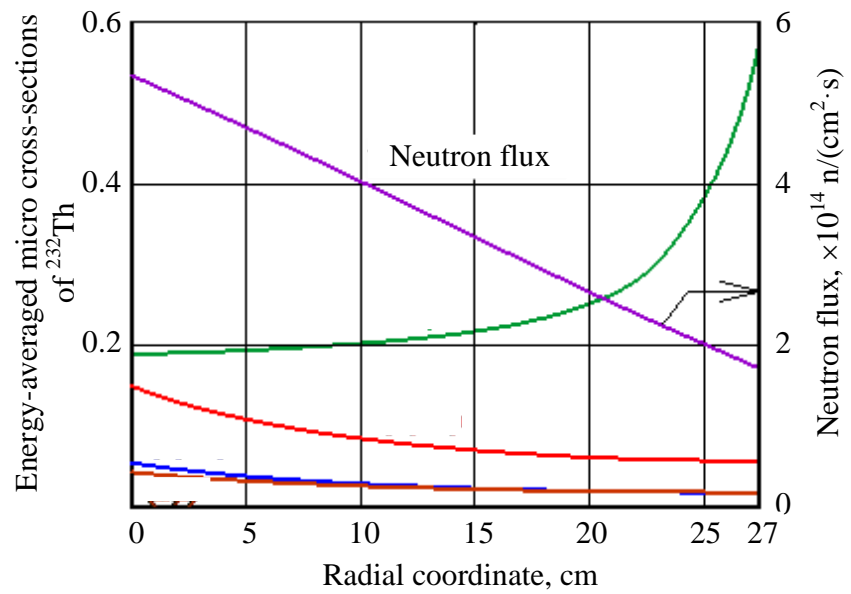

Fig. 3. Energy-averaged micro cross-sections of ${ }^{232} \mathrm{Th}$ and neutron flux in Th-blanket: $-\longrightarrow(n, \gamma),-(n, 2 n),-(n, 3 n)$, $-(n, f)$ timizing the blanket thickness and thorium inventory should be set and solved.

The cross-section of ${ }^{232} \mathrm{Th}(n, f)$ reaction is more or less similar to the micro cross-section of the ${ }^{232} \mathrm{Th}(n$, $3 n$ ) reaction, meaning that the thorium fission reaction is weaker than reactions giving rise to the ${ }^{233} \mathrm{U},{ }^{231} \mathrm{~Pa}$ and ${ }^{232} \mathrm{U}$ isotopes. This fact allowed us to expect modest heat generation rates in the Th-blanket that would simplify heat removal from it. Therefore, thermal energy release into the environment without utilization may be economically reasonable.

The balance of energy-averaged reaction rates in Th-blanket is presented in Fig. 4. The processes involved include radiative neutron capture by of ${ }^{232} \mathrm{Th}$, fission reaction of ${ }^{232} \mathrm{Th},{ }^{232} \mathrm{Th}(n, 2 n)$ and ${ }^{232} \mathrm{Th}(n, 3 n)$ threshold reactions, radiative neutron capture reactions of structural materials ( $\mathrm{Fe}, \mathrm{Mo}$ ) and neutron leakage. In fact, these

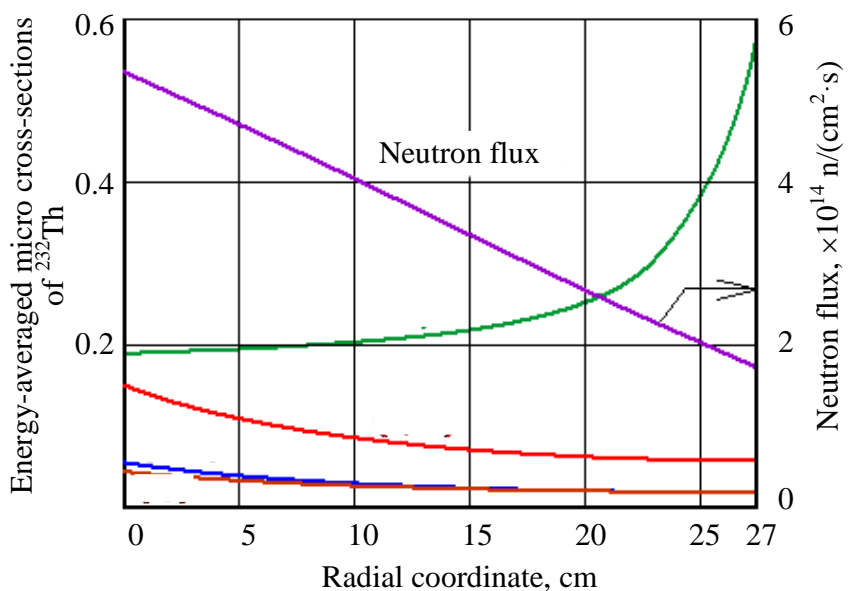

Fig. 4. Energy-averaged reaction rates and neutron leakage rate in Th-blanket: $-\longrightarrow(n, \gamma),-\longrightarrow(n, 2 n),--(n, 3 n)$, $-(n, f)$ the ${ }^{233} \mathrm{U}$ production rate at the blanket periphery is substantially higher than the production rates of ${ }^{231} \mathrm{~Pa}$ and ${ }^{232} \mathrm{U}$ isotopes. Therefore, enhancing the production of the desired isotopes may require a thinner blanket. Third, the ${ }^{232} \mathrm{Th}(n, f)$-reaction is slow in all radial points of the Th-blanket. Then one may anticipate that heat could be dumped into the environment without the need to be utilized. Fourth, the neutron balance is strongly influenced by the rate of neutron leakage, especially that occurring deep in the blanket.

Rates ofreactions involved in the isotope decay chain. This section analyses the rates of neutron reactions involved in the chain of isotopic transformations in the Th-blanket. The rates of radioactive decay, radiative neutron capture reaction and fission reaction for some short-lived isotopes are presented in Table 1. 
T a b l e 1. Reaction rates (1/day) of short-lived isotopes from the decay chain of Th-blanket.

\begin{tabular}{c|c|c|c|c}
\hline Isotope & $\lambda$ & $\left(\sigma_{c} \cdot \Phi\right)$ & $\left(\sigma_{f} \Phi\right)$ & $\left(\sigma_{c f} \Phi\right)$ \\
\hline${ }^{231} \mathrm{Th}$ & 0.64 & 0.000206 & 0.000045 & 0.000251 \\
${ }^{233} \mathrm{Th}$ & 45.0 & 0.000174 & 0.000008 & 0.000182 \\
${ }^{232} \mathrm{~Pa}$ & 0.53 & 0.000077 & 0.000230 & 0.000307 \\
${ }^{233} \mathrm{~Pa}$ & 0.026 & 0.000125 & 0.000002 & 0.000127 \\
\hline
\end{tabular}

One can see that radioactive decay rates are at least twice as high as the rate of radiative neutron capture. For this reason, the composition analysis of an isotope mix produced in the Th-blanket may neglect the radiative neutron capture and fission of those short-lived nuclides. If structural materials with an enhanced radiation resistance are used in the first wall, then the neutron load (and related neutron flux) can be increased, while the reaction rate difference can be decreased. However, a several-fold neutral flux increase is hardly practicable.

Next, we compared reaction rates obtained with different cross-sections, i.e. macro cross-sections multiplied on neutron fluxes. We omitted the same multiplier (neutron flux) and calculated the macro cross-sections using relative masses of the isotopes (kg per $1 \mathrm{MT}{ }^{232} \mathrm{Th}$ ) produced, for example, by the end of the 1000-day irradiation cycle rather than isotope concentrations, considering the close atomic weights of nuclides involved in the chain.

The rates of ${ }^{232} \mathrm{U}$ production via the threshold ${ }^{232} \mathrm{Th}(n, 2 n){ }^{231} \mathrm{~Pa}(n, \gamma),{ }^{232} \mathrm{Th}(n, 3 n){ }^{230} \mathrm{Th}(n, \gamma){ }^{231} \mathrm{~Pa}(n, \gamma)$ reactions and via ${ }^{232} \mathrm{Th}(n, \gamma){ }^{233} \mathrm{U}(n, 2 n)$ reaction were calculated. The threshold reactions are comparable in terms of their contributions to the ${ }^{231}$ Th production (in the form of a direct $(n, 2 n)$ threshold reaction on ${ }^{232}$ Th nuclei in one case and through neuron capture by ${ }^{230} \mathrm{Th}$ in the other case). The total rate of these threshold reactions was compared with rates of the ${ }^{231} \mathrm{~Pa}(n, \gamma)$ reaction and rate of threshold ${ }^{233} \mathrm{U}(n, 2 n)$ reaction. The micro crosssections, relative masses and reaction rates at the end of irradiation time (1000 days) are presented in Table 2.

$\mathrm{T}$ a b 1 e 2 . The rate of ${ }^{232} \mathbf{U}$ production via different channels

\begin{tabular}{c|c|c|c|c}
\hline${ }^{232}$ Th-reaction & Evaluated reaction & Micro cross-section, barn & Relative mass, $\mathrm{kg} / t$ & Reaction rate, barn $\cdot \mathrm{kg}$ \\
\hline$(n, 2 n)$ & ${ }^{232} \mathrm{Th}(n, 2 n)$ & 0.082 & 988.6 & 80.9 \\
$(n, 3 n)$ & ${ }^{230} \mathrm{Th}(n, \gamma)$ & 3.679 & 0.911 & 3.35 \\
$(n, 2 n)+(n, 3 n)$ & ${ }^{231} \mathrm{~Pa}(n, \gamma)$ & 6.167 & 2.564 & 15.81 \\
$(n, \gamma)$ & ${ }^{233} \mathrm{U}(n, 2 n)$ & 0.010 & 6.188 & 0.063 \\
\hline
\end{tabular}

It is evident from this table that the total rate of the threshold reactions, is more than twice as high as the ${ }^{232} \mathrm{Th}(n, \gamma){ }^{233} \mathrm{U}(n, 2 n)$-reaction rate. The ${ }^{232} \mathrm{Th}(n, 2 n)$-reaction is 24 times faster than the ${ }^{232} \mathrm{Th}(n, 3 n)$-reaction. As a result, the lion's share of ${ }^{232} \mathrm{U}$ is produced via the ${ }^{232} \mathrm{Th}(n, 2 n)$-reaction. The contributions of the rest reactions are negligible.

Some parameters of heat generation rate at the end of irradiation time are presented in Table 3. Isotope ${ }^{233} \mathrm{U}$ is main contributor here while contribution of ${ }^{232} \mathrm{Th}$ is lower by two orders of magnitude. Taking into account the fact that ${ }^{232} \mathrm{Th}$ is a threshold-fissionable isotope, and that Th-blanket contains $99.86 \%{ }^{232} \mathrm{Th}$, one can conclude that total heat generation rate at the end of irradiation time remains insignificant. Therefore, heat removal does not represent a serious problem, as thermal energy may be released into the environment without the need to be utilized

$\mathrm{T}$ a $\mathrm{b} 1 \mathrm{e}$ 3. Fission reaction rates for different isotopes at the end of irradiation time (1000 days)

\begin{tabular}{c|c|c|c}
\hline Isotope & Micro cross-section of fission, barn & Relative mass, $\mathrm{kg} / t$ & Fission rate, barn·kg \\
\hline${ }^{232} \mathrm{Th}$ & 0.025 & 998.6 & 25.26 \\
${ }^{230 \mathrm{Th}}$ & 0.057 & 0.911 & 0.052 \\
${ }^{231} \mathrm{~Pa}$ & 0.256 & 2.564 & 0.656 \\
${ }^{232} \mathrm{U}$ & 3.429 & 0.089 & 0.305 \\
${ }^{233} \mathrm{U}$ & 7.477 & 6.188 & 46.27 \\
${ }^{234} \mathrm{U}$ & 0.455 & 0.072 & 0.033 \\
\hline
\end{tabular}

Thus, one can conclude that contribution of short-lived isotopes is negligibly small. Among the threshold reactions, only the ${ }^{232} \mathrm{Th}(n, 2 n)$ should be accounted for. 
Thorium burnup. Time-dependent thorium burnup via different reactions (radiative neutron capture, fission, threshold $(n, 2 n)$ - and $(n, 3 n)$-reactions) is shown in Fig. 5.

Naturally, all time dependencies are linear, because the rates of all burnup reactions are linear functions of the neutron flux and neutron spectrum. The neutron flux is determined by the FNS intensity which is fixed with re-

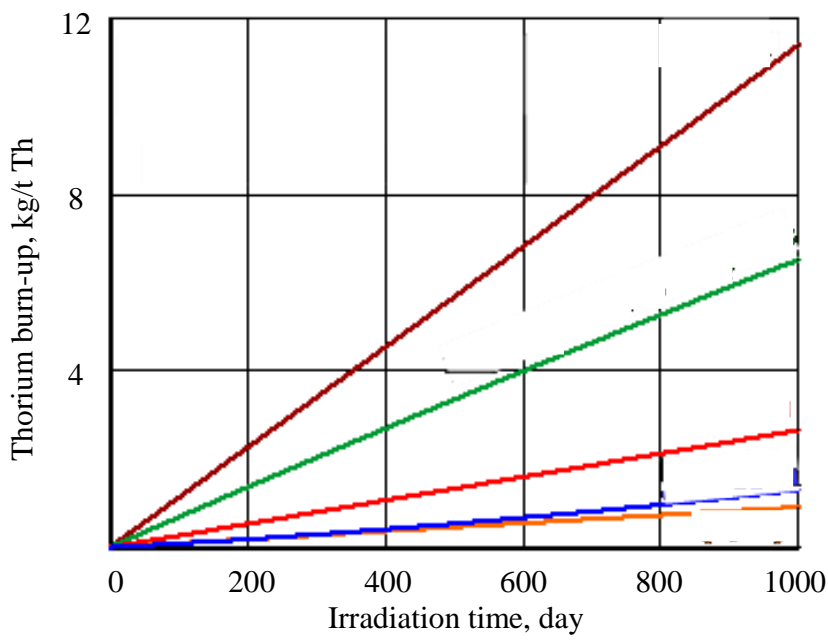

Fig. 5. Thorium burnup via different reactions as a function of irradiation time: —— total, —— radiative capture, - $(n, 2 n),-$ fission, $-\longrightarrow(n, 3 n)$

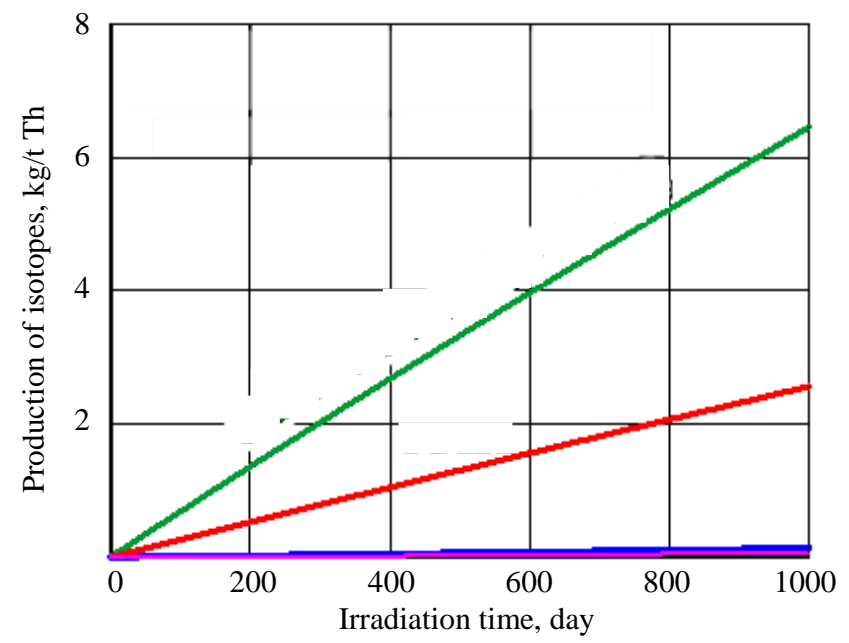

Fig. 6. Production of isotopes as a function of irradiation time: $-{ }^{233} \mathrm{U}+{ }^{231} \mathrm{~Pa}\left(T_{1 / 2}=27\right.$ days $),-\longrightarrow{ }^{231} \mathrm{~Pa},--{ }^{232} \mathrm{U}$, $-{ }^{234} \mathrm{U}$

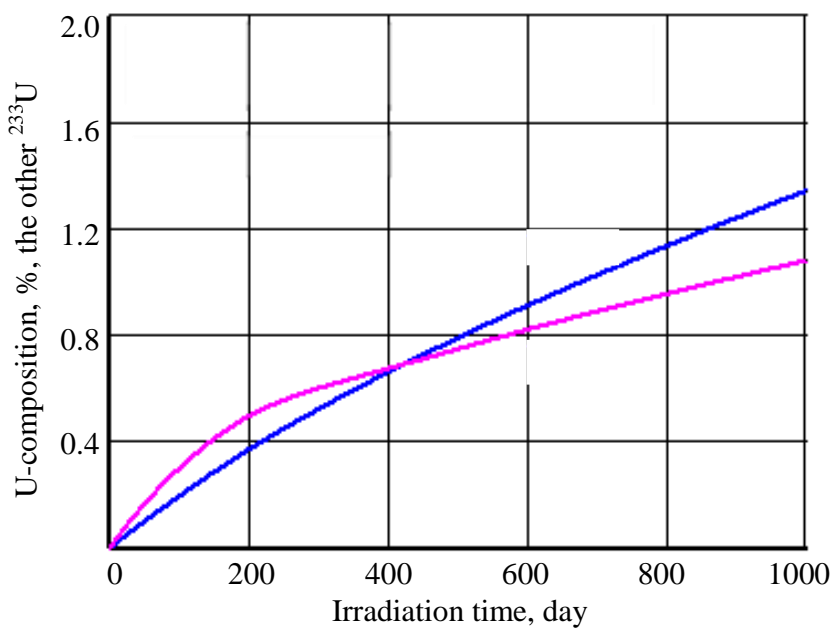

Fig. 7. Isotope composition of uranium as a function of irradiation time: $-\simeq{ }^{232} \mathrm{U},-\longrightarrow{ }^{234} \mathrm{U}$ spect to the first wall fusion neutron load $\left(1 \mathrm{MW} / \mathrm{m}^{2}\right)$. Time-dependent variations of neutron spectrum are very small because of low thorium burnup and low accumulation of new isotopes. Only around $10 \mathrm{~kg}$ out of one initial ton ${ }^{232} \mathrm{Th}$ input are burned up during an irradiation cycle, meaning that ${ }^{232}$ Th burnup is nearly $1 \%$ of heavy metal (HM) inventory. Mean fuel burnup in current light-water reactors of VVER-1000 type is close to $5 \% \mathrm{HM}$ while maximal fuel burnup is about $7 \% \mathrm{HM}$. The ways towards intensification of thorium burnup and production of objective isotopes must include the attempts to provide higher values of neutron load on the first HTR wall and longer irradiation time of Thblanket. Anyway, it is necessary to seek for new structural materials with upgraded radiation resistance.

As expected, the ${ }^{232} \operatorname{Th}(n, \gamma)$-reaction is the main channel for thorium burnup. However, the ${ }^{232} \mathrm{Th}(n, 2 n)$ threshold channel is not negligibly weak, and slightly more intense than ${ }^{232} \mathrm{Th}(n, f)$ channel. These results allowed us to expect intense production of traditional isotope ${ }^{233} \mathrm{U}$ and non-traditional objective isotopes ${ }^{231} \mathrm{~Pa}$ and ${ }^{232} \mathrm{U}$

Production of isotopes ${ }^{233} \mathrm{U},{ }^{231} \mathrm{~Pa}$ and ${ }^{232} \mathrm{U}$. Production of different isotopes in thorium blanket under irradiation by fusion neutrons is shown in Fig. 6 as a function of irradiation time.

We show ${ }^{233} \mathrm{U}$ and ${ }^{233} \mathrm{~Pa}$ total production considering that ${ }^{233} \mathrm{~Pa}$ decays into ${ }^{233} \mathrm{U}$ (half-life $T_{1 / 2}\left({ }^{233} \mathrm{~Pa}\right)=27$ days $)$ almost fully. In fact, its radioactive decay is much faster than its radiative neutron capture and fission. As expected, the largest part of ${ }^{233} \mathrm{U}$ is produced via the ${ }^{232} \mathrm{Th}$ radiative neutron capture, followed by two rapid $\beta$-decays of ${ }^{233} \mathrm{Th}$ and ${ }^{233} \mathrm{~Pa}$. However, ${ }^{231} \mathrm{~Pa}$ produced via the ${ }^{232} \mathrm{Th}(n, 2 n)$ threshold reaction constitutes a significant portion of the ${ }^{233} \mathrm{U}$ produced. The production of the «next in the line» isotopes ${ }^{232} \mathrm{U}$ and ${ }^{234} \mathrm{U}$ via the ${ }^{231} \mathrm{~Pa}(n, \gamma)$ - and ${ }^{233} \mathrm{U}(n, \gamma)$ reactions, respectively, is, of course, less substantial.

Isotopic composition of uranium produced. The ${ }^{232} \mathrm{U}$ and ${ }^{234} \mathrm{U}$ contentsin the uranium produced in Thblanket are shown in Fig. 7 as functions of irradiation time.

One can see that the ${ }^{232} \mathrm{U}$ and ${ }^{234} \mathrm{U}$ contents increase almost linearly with time. At the end of the 1000-day irradiation time, they reach 1.6 and $1 \%$, respectively. ${ }^{233} \mathrm{U}$ represents the remaining $97.4 \%$. In fact, highly-enriched weapon-grade uranium is produced in the irradiated thorium blanket. This material is very important for nuclear power reactors and re- 
quires strict control (in the non-proliferation context) by the IAEA inspectorate. The produced weapon-grade uranium may be diluted by either natural or depleted uranium to a required concentration of fissile ${ }^{233} \mathrm{U}$. In addition, such a dilution can provide proliferation resistance of the produced uranium at the highest isotopic level. In this case, main fissile isotope ${ }^{233} \mathrm{U}$ would be surrounded by the lighter ${ }^{232} \mathrm{U}$ and by the heavier ${ }^{234} \mathrm{U}$ and ${ }^{238} \mathrm{U}$ isotopes.

Now a question about the ${ }^{234} \mathrm{U}$ and ${ }^{232} \mathrm{U}$ contents of the uranium produced, 1 and $1.4 \%$, respectively: are they large or small? Numerical evaluations suggest that these concentrations are negligible and unable to influence the neutron-physical properties of nuclear fuel in any significant way, as produced uranium would be diluted by ${ }^{238} \mathrm{U}$. Moreover, with the uranium produced and diluted by natural / depleted uranium to $5 \%{ }^{233} \mathrm{U}$, the ${ }^{232} \mathrm{U}$ and ${ }^{234} \mathrm{U}$ concentrations fall $\sim 25$ times to 0.065 and $0.04 \%$, respectively.

Presently, the glovebox approach is used to fabricate fresh nuclear fuel for light-water reactors from reprocessed uranium. According to the Russian technical regulations, the ${ }^{234} \mathrm{U}$ content in the reactor-grade uranium must be below $0.2 \%$. The rationale behind this stringent requirement resides in the ${ }^{234} \mathrm{U}$ intense $\alpha$-activity $\left(T_{1 / 2}=2.45 \cdot 10^{5}\right.$ years). If uranium is enriched using a gas-diffusion or gas-centrifuge technology, then $\alpha$-particles emitted by ${ }^{234} \mathrm{U}$ are able to disorder the enriching process by the chemical dissociation of uranium hexafluoride $\mathrm{UF}_{6}$ molecules accompanied by the formation of free fluorine and lower uranium fluorides (mainly, $\mathrm{UF}_{5}$ and $\mathrm{UF}_{4}$ ). These low-volatile uranium fluorides can disturb the uranium enriching process, as they can precipitate on the inner surfaces of process facilities (centrifuges, pipelines), while free fluorine can act as a strong corrosion-aggressive element.

As for ${ }^{232} \mathrm{U}$, Russian technical regulations require that the ${ }^{232} \mathrm{U}$ content in uranium-bearing materials is below $2 \cdot 10^{-7} \%$. The rationale is largely the same as that for ${ }^{234} \mathrm{U}$, although a much stronger case can be considered for ${ }^{232} \mathrm{U}$. Indeed, the ${ }^{232} \mathrm{U}$ half-live is significantly shorter than that of ${ }^{234} \mathrm{U}$ ( 69 years versus $2.45 \cdot 10^{5}$ years). The ${ }^{232} \mathrm{U}$ decay chain includes five additional $\alpha$-emitters. Besides, one member of ${ }^{232} \mathrm{U}$ decay chain, namely isotope ${ }^{208} \mathrm{Tl}$, is a source of high-energy $(2.6 \mathrm{MeV}) \gamma$-rays. At the end of irradiation time (1000 days), the ${ }^{232} \mathrm{U}$ content in the uranium produced is $\sim 10^{7}$ times larger than the acceptable value for the glovebox technology of U-based fuel fabrication. Even if the uranium produced is diluted by ${ }^{238} \mathrm{U}$, the ${ }^{232} \mathrm{U}$ content is at least $\sim 10^{5}$ times greater than acceptable value $\left(2 \cdot 10^{-7} \%\right)$ t. This means that remote technologies should be developed for nuclear fuel fabrication from uranium with such isotope composition. The intense emission of high-energy $\gamma$-rays can act as a strong deterrent for parties who might otherwise be willing to use uranium for non-peaceful applications. If such parties still go for the manufacturing of a nuclear explosive device (NED), they will have to carry out uranium pre-enriching with isotope ${ }^{233} \mathrm{U}$ in a cascade of gas centrifuges, for instance. In this case, intense $\alpha$-activity of ${ }^{232} \mathrm{U}$ and its decay products could trigger a chemical dissociation of the $\mathrm{UF}_{6}$ molecules. The separation of the ${ }^{233} \mathrm{U}$ isotope, surrounded by ${ }^{232} \mathrm{U},{ }^{234} \mathrm{U}$ и ${ }^{238} \mathrm{U}$, is a much more intricate problem than the enrichment of natural uranium. Tо solve it, one would need a dedicated or a two-stage enrichment cascade to produce successively higher concentrations of the desired isotope. Besides, difference of ${ }^{232} \mathrm{U},{ }^{233} \mathrm{U}$ and ${ }^{234} \mathrm{U}$ atomic weights is only 1 a.m.u. while that in the process of natural uranium enrichment equals to 3 a.m.u. So small difference can complicate additionally the uranium enriching process and reduce efficiency of the process. If terrorists try to manufacture a NED without the ${ }^{233} \mathrm{U}$ separation, then intense heat generation by ${ }^{232} \mathrm{U}$ would melt down the chemical explosive, disabling the NED. The intense neutron emission by ${ }^{232} \mathrm{U}$ from spontaneous fission reactions can trigger a premature initiation of chain fission reaction in the NED and drastically reduce the energy yield of nuclear explosion. Thus, the large ${ }^{232} \mathrm{U}$ content is an extremely strong barrier against any unauthorized usage of the ${ }^{233} \mathrm{U}$.

The technical capabilities of the governmentowned industrial enterprises are evidently greater than those of terrorist organizations. Actually, we can always establish the ${ }^{232} \mathrm{U}$ content in uranium-bearing materials, which would allow the government-owned enterprises to work with these materials, but make them beyond the reach of non-state actors.

Production of ${ }^{231} \mathbf{P a}$. Ratio of ${ }^{231} \mathrm{~Pa}$-to-uranium content in Th-blanket is shown in Fig. 8 as a function of irradiation time.

One can see that the ${ }^{231} \mathrm{~Pa}-\mathrm{to}-\mathrm{U}$ ratio is, in essence, a time-independent value (about 0.38). This

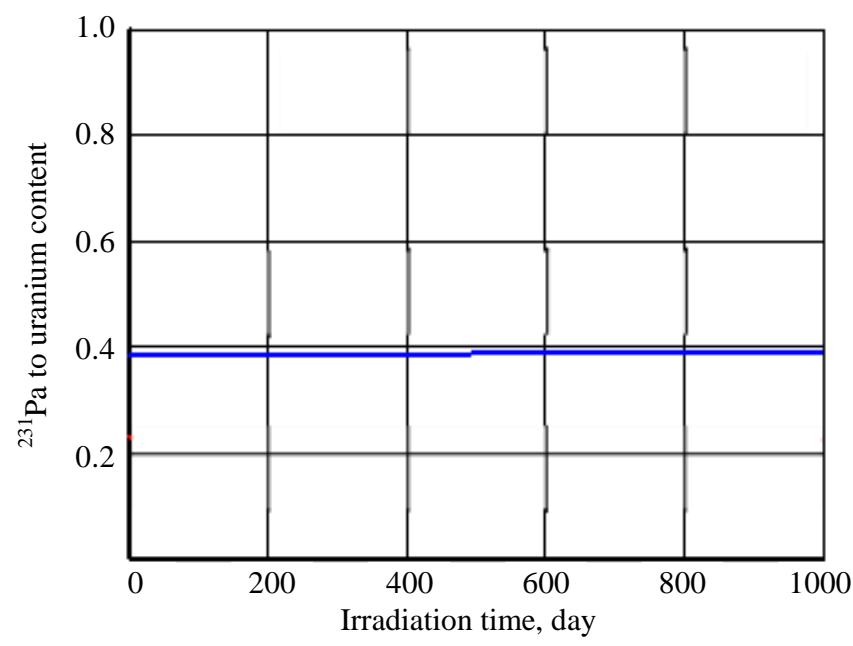

Fig. 8. Ratio of ${ }^{231} \mathrm{~Pa}-\mathrm{to}-\mathrm{U}$ content as a function of irradiation time 
means that with uranium enriched up to $<5 \%{ }^{233} \mathrm{U}$ the ${ }^{231} \mathrm{~Pa}$ content in uranium-bearing materials will be $1.9 \%$. We know that the neutron capture micro cross-section for ${ }^{231} \mathrm{~Pa}$ is almost 75 times higher than for ${ }^{238} \mathrm{U}$ in the thermal energy range. Therefore, an intense neutron capture by ${ }^{231} \mathrm{~Pa}$ can contribute to the neutron balance and stabilize neutron-multiplying properties of uranium-based fuels during irradiation time in a nuclear power reactor.

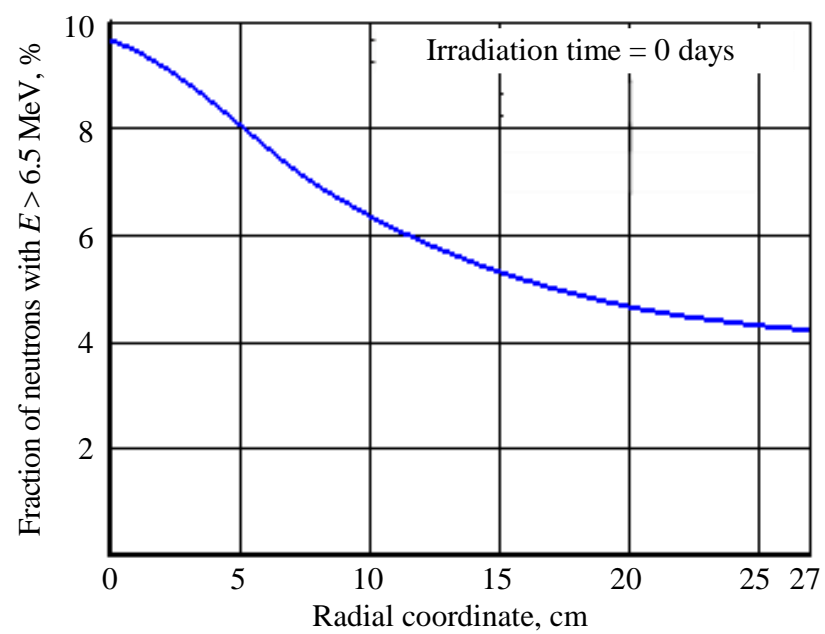

Fig. 9. Fraction of high-energy neutrons in thorium blanket (radia distribution)

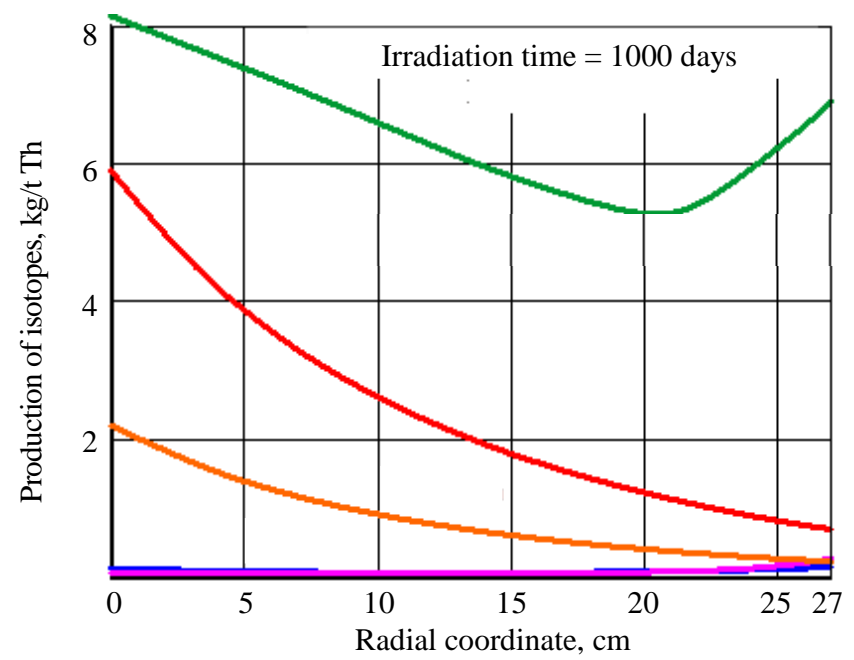

Fig. 10. Radial distributions of isotope production in thorium blanket: $-—{ }^{233} \mathrm{U}+{ }^{231} \mathrm{~Pa}\left(T_{1 / 2}=27\right.$ days $),-\longrightarrow{ }^{231} \mathrm{~Pa}$, $-{ }^{230} \mathrm{Th},-\longrightarrow{ }^{232} \mathrm{U},-\longrightarrow{ }^{234} \mathrm{U}$

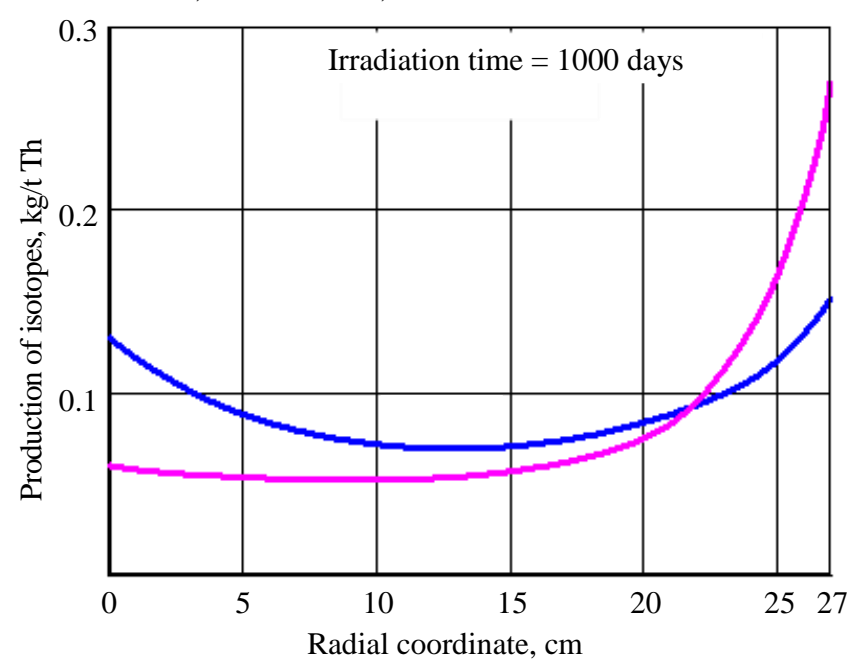

Fig. 11. Uranium isotope composition in Th-blanket: - ${ }^{232} \mathrm{U},--{ }^{234} \mathrm{U}$
Fraction of high-energy neutrons in Th-blanket. Because the desired ${ }^{231} \mathrm{~Pa}$ and ${ }^{232} \mathrm{U}$ isotopes are produced by threshold $(n, 2 n)$ - and $(n, 3 n)$-reactions, it would be interesting to study the radial distribution of high-energy neutrons in thorium blanket. Only these high-energy neutrons are able to initiate threshold $(n, 2 n)$ - and $(n, 3 n)$ reactions. As was shown in Fig. 5, the neutron spectrum does not change in any significant way during full irradiation time because of the ${ }^{232} \mathrm{Th}$ low burn-up (about $1.1 \% \mathrm{HM})$. For this reason, the radial distribution of high-energy neutrons in thorium blanket is shown in Fig. 9 for the beginning of irradiation.

Fraction of high-energy $(E>6.5 \mathrm{MeV})$ neutrons declines approximately twice as we move from the front edge of the Th-blanket (the plasma-blanket border) to its back edge (the blanket-structure border). The radial degradation of the high-energy neutron flux is due to the gradual neutron slowing down through elastic and inelastic scattering. Therefore all relevant isotopes, including those desired, will be accumulated in thorium blanket in a non-uniform spatial manner. This conclusion is confirmed by numerical results presented below.

Isotope production in thorium blanket. The radial distributions of isotope production in thorium blanket are shown in Fig. 10.

One can see that the production of the desired ${ }^{231} \mathrm{~Pa}$ and ${ }^{230} \mathrm{Th}$ isotopes, which is only achievable with highenergy neutrons via threshold $(n, 2 n)$ - and $(n, 3 n)$ reactions, is substantially ( $\sim$ by a factor of 6 ) more intense at the front edge than at the back edge of thorium blanket. This can be due to the neutron spectrum softening (see Fig. 9), i.e. slowing down of high-energy neutrons in the energy range below $6.5 \mathrm{MeV}$. The production of the «traditional» ${ }^{233} \mathrm{U}$ isotope initially declines, but ultimately starts rising. Such an irregular trajectory of the ${ }^{233} \mathrm{U}$ production may be due to the fact that moderated neutrons enter an energy range $(1-100 \mathrm{eV})$, where the ${ }^{232} \mathrm{Th}$ neutron capture cross section is low, which is favorable to the production of ${ }^{233} \mathrm{U}(1 \mathrm{eV}$ to $100 \mathrm{eV})$. However, this effect calls for further investigations.

The production of ${ }^{232} \mathrm{U}$ and ${ }^{234} \mathrm{U}$ is so small that the radial distributions of these isotopes are almost indistinguishable in Fig. 10. These distributions are treated separately in the next section.

Radial distribution of uranium isotope composition in Th-blanket. The radial distributions of uranium isotopes $\left({ }^{232} \mathrm{U}\right.$ and $\left.{ }^{234} \mathrm{U}\right)$ production in Th-blanket are presented in Fig. 11. 
The ${ }^{232} \mathrm{U}$ production minimum in the middle of thorium blanket is due to the neutron spectrum softening. However, the ${ }^{232} \mathrm{U}$ production begins to increase in the peripheral layers of thorium blanket. This may be attributed, first, to the intense production of ${ }^{233} \mathrm{U}$ at the blanket periphery (see Fig. 10), second, by the initiation of threshold ${ }^{233} \mathrm{U}(n, 2 n){ }^{232} \mathrm{U}$-reaction. The production of ${ }^{234} \mathrm{U}$ increases substantially closer to the blanket back edge. This can also be due to the vigorous generation of ${ }^{233} \mathrm{U}$ and the ${ }^{233} \mathrm{U}(n, \gamma){ }^{234} \mathrm{U}$-reaction.

\section{COMPARISON WITH OTHER CALCULATIONS}

Production of various isotopes in Th-blanket of HTR on D-T-plasma has been also investigated in papers $[9,10]$. Experimental and computational data on reaction rates per one fusion neutron $(E=14 \mathrm{MeV})$ are presented in Table 4 . These results demonstrate sufficiently good agreement.

$\mathrm{T}$ a b 1 e 4. Reaction rates of ${ }^{232}$ Th per one $14-\mathrm{MeV}$ neutron

\begin{tabular}{c|c|c}
\hline${ }^{232}$ Th reactions & Experiment [9] & Calculation [10] \\
\hline$(n, \gamma)$ & $1.63 \pm 0.10$ & 0.58 \\
$(n, 2 n)$ & $0.42 \pm 0.04$ & 0.15 \\
$(n, 3 n)$ & $0.30 \pm 0.05$ & 0.19 \\
$(n, f)$ & $0.17 \pm 0.01$ & 0.76 \\
\hline
\end{tabular}

The time-dependent variations of isotopic mixes produced in a thorium HTR blanket are shown in Fig. 12 [10]. They show a good qualitative agreement with the results published in [10]. Small discrepancies may be due to dissimilar HTR types, HTR blanket designs, different ENDF libraries and numerical approximations.

\section{CONCLUSION}

The proposed model of fusion neutron source makes it possible to form high-energy neutron

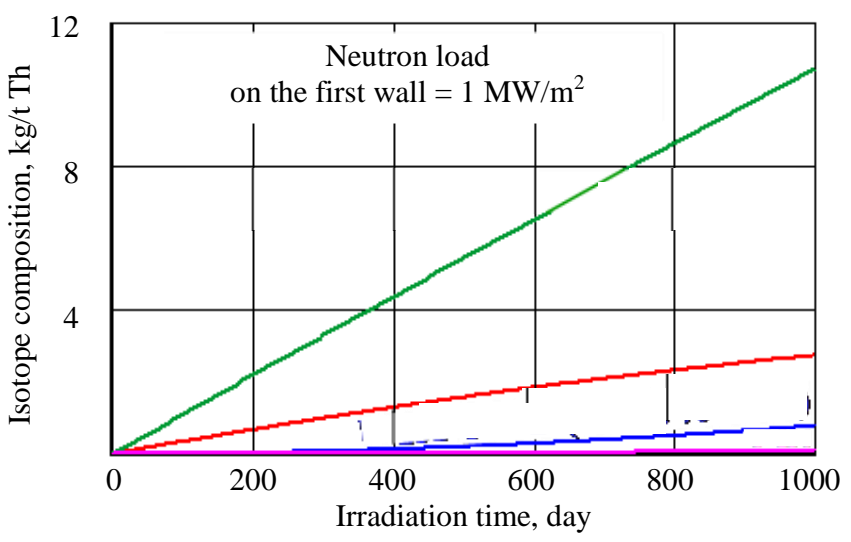

Fig. 12. Isotope composition of Th-blanket as a function of irradia-

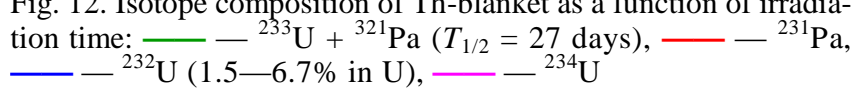
spectrum in Th-blanket with sufficient fraction of 14-MeV neutrons.

It was demonstrated that non-traditional target isotopes ${ }^{231} \mathrm{~Pa}$ and ${ }^{232} \mathrm{U}$ can be produced insignificant quantities via threshold $(n, 2 n)$ - and $(n, 3 n)$-reactions.

A possibility was shown to use simplified chain of isotope transformations without taking short-lived isotopes into consideration. Only one ${ }^{232} \mathrm{Th}(n, 2 n)$-reaction should be accounted for.

The production of the desired isotopes was shown to reduce significantlyas it goes deeper into thorium blanket. It therefore seems reasonable to look for an optimal blanket thickness and the natural thorium inventory in the blanket.

\section{Acknowledgments}

The reported study was funded by RFBR, project № 19-29-02006.

\section{REFERENCES}

1. Kulikov G.G., Shmelev A.N., Geraskin N.I., Kulikov E.G., Apse V.A. Advanced nuclear fuel cycle for the RF using actinides breeding in thorium blankets of fusion neutron source. - Nuclear Energy and Technology, 2016, vol. 2, p. 147-150.

2. Shmelev A.N., Kulikov G.G. On the role of fusion neutron source with thorium blanket in forming the nuclide composition of the nuclear fuelcycle of the Russian Federation. - Physics of Atomic Nuclei, 2016, vol. 79, p. 1508-1512.

3. Baatar T., Kulikov E.G. Justification of VVER-1000 safety when using fuel compositions doped by protactinium and neptunium. - Izv. Wysshikh Uchebnykh Zawedeniy. Yad. Energ., 2020, vol. 1, p. 26-36. 
4. Kulikov G.G., Shmelev A.N., Kulikov E.G., Apse V.A. Proliferation-protected, ultra-high burnup reactor fuel produced in the thorium blanket of a fusion neutron source Global. - In: International Nuclear Fuel Cycle Conference and TOP FUEL 2019. Light Water Reactor Fuel Performance Conference, p. 1088-1092.

5. Orlov V.V., Shatalov G.E., Marin S.V. Evolution of fuel isotope composition in thorium blanket of hybrid thermonuclear reactor. - Report of Kurchatov Institute on Nuclear Energy, 1979, p. 29-30.

6. Leppänen J., Kaltiaisenaho T. Expanding the use of serpent 2 to fusion applications: shut-down dose rate calculations. - In: International Conference on the Physics of Reactors PHYSOR 2016.

7. Yudong L., Guangming Z., Francisco A.H., Pavel P., Jaakko L., Minyou Y. Benchmark of Serpent-2 with MCNP. - Application to European DEMO HCPB Breeding Blanket, 2020, vol. 155, p. 111583.

8. Riku T., Ville V., Jaakko L. New energy deposition treatment in the Serpent-2 Monte Carlo transport code. - Annals of Nuclear Energy, 2019, vol. 129, p. 224-232.

9. Shief H.E. J. et al. Measurements of the Reaction Rate Distributions Produced in a Large Thorium Cylinder by a Central Source of DT Neutrons. — United Kingdom Atomic Energy Authority, 1977.

10. Krumbein A., Lemanska M., Segev M., Wagschal J.J., Yaari A. Reaction rate calculations in uranium and thorium blankets surrounding a central deuterium — tritium neutron source. — Nuclear Technology, 1980, vol. 48, p. 110—116.

\section{AUTHORS}

Gennadij Genrichovich Kulikov. leading engineer, PhD in Physics \& Mathematics; National Research Nuclear Univ. MEPhI, 115409 Moscow, Kashirskoe sh. 31, Russia, ggkulikov@mephi.ru

Anatolij Nikolaevich Shmelev, professor, Dr. of Science Degree in Engineering; National Research Nuclear Univ. MEPhI, 115409 Moscow, Kashirskoe sh. 31, Russia, shmelan@mail.ru

Anton Evgenievich Kruglikov, engineer; National Research Nuclear Univ. MEPhI, 115409 Moscow, Kashirskoe sh. 31, Russia, aekruglikov@mephi.ru

Vladimir Aleksandrovich Apse, engineer, PhD in Engineering; National Research Nuclear Univ. MEPhI, 115409 Moscow, Kashirskoe sh. 31, Russia, apseva@mail.ru

Evgenij Gennadievich Kulikov, Associate Professor, PhD in Engineering; National Research Nuclear Univ. MEPhI, 115409 Moscow, Kashirskoe sh. 31, Russia, egkulikov@mephi.ru

Received 15 January 2021

Revised 16 March 2021

Accepted 25 March 2021

Problems of Atomic Science and Technology Ser. Thermonuclear Fusion, 2021, vol. 44, issue 2, pp. 124-132 